\title{
The effect of self-esteem on the willingness to pay tax
}

\author{
PIROSKA DOBOS ${ }^{1}$
}

KATALIN TAKÁCSNÉ GYÖRGY²

\begin{abstract}
Many studies examine the relationship between money and self-esteem, two factors that people tend to as pire for. In addition, there are studies in the special literature on the examination of low self-esteem and greater risk of breaking the law. If we consider the concealment of income, the payment of less tax than owed or the complete avoidance of tax payment to be a form of gainingmoney, we can assume that there is a direct link between tax evasion and self-esteem, similar to the relationship between money and self-esteem. Based on this assumption, we investigated the direct relationship between self-esteem and tax evasion, tax avoidance and tax denial and, using Rosenberg's self-esteem scale, in order to find out whether the degree of self-esteem ofan individual can affect their joining the hidden economy. The aim of the research was to compile a questionnaire that explores unethical business behaviour, addressing the causes of the black economy from an economic psychological aspect. The results of the evaluation of the questionnaire are presented in the study.
\end{abstract}

\section{Keywords}

self-esteem, self-respect, attitude, tax moral, tax evasion, willingness to pay tax, behavioural economics, economic psychology

\footnotetext{
${ }^{1}$ Óbuda University, Doctoral School on Safety and Security Sciences, 1081 Budapest, Hungary, 8 Népszínház St. d.piri@globalprofit.hu,+36704561812

2 Óbuda University, Keleti Károly Faculty, Institute of Management and Organisation, 1081 Budapest, Hungary, 8 NépszínházSt. takacsnegyorgy.katalin@kgk.uni-obuda.hu, +3616665360
} 